\title{
COMPARISON AND ANALYSIS OF DIFFERENT 3D PRINTING TECHNIQUES
}

\author{
Sandeep (Corresponding Author) $)^{1} \&$ Deepak Chhabra ${ }^{2}$
}

\begin{abstract}
The main aim of this work is to compare and critically analyze different 3D printing techniques which are still in its commencement stage to fabricate parts at a mass scale in industrial applications. The significant parameters for various 3D printing techniques have been discussed. The suitability of different 3D printing techniques in various applications has been argued. A methodical review shows that 3D printing techniques have been developed to such a level that these can be used in the field of manufacturing ranging from prototype to a casting and then the final product. It has been observed that most common significant parameters of all additive manufacturing techniques are layer thickness, build orientation, and build time, temperature, laser speed and number of contours. A critical comparison between various techniques shows that a 3D printing technique has superior for one application and same technique has limitations for another purpose, according to types of materials, availability of materials, size, cost, printing machine and performance of fabricated parts.

Keywords:- comparison and analysis, process parameters, layer thickness, laser power, build orientation, build time, SLA, FDM, SLS, SLM .
\end{abstract}

\section{INTRODUCTION}

A technology that can bring new revolution in manufacturing industry is 3D printing or rapid prototyping (RP) which includes adding successive layers of desired material for making three dimensional solid object or prototype from a virtual design, so additive nature of this technology as opposed to subtractive nature has given new name i.e. additive manufacturing (AM). 3D printing is actually making a physical product by converting the CAD model into desired part by deposing layer by layer material through a computerized control nozzle. The 3D printing technology applications are not far away from manufacturing, construction, medical, electronics, defense and food industry where it is not only used for making models and prototype but also different assembly parts. Different 3D printing techniques such as Stereolithography, FDM, SLS, SLM, LOM are available for making parts within a short period of time and with desired good quality regarding characteristics regarding performance and materials. 3D printing in comparison to $2 \mathrm{D}$ printing builds three dimensional parts, consequently layer by layer deposition on top of each other. Firstly, in 3D printing a geometrical shape of any part is made in CAD software and then this part is sliced into a series of parallel cross-section pieces with also generating the curing or binding path. The part is then generated by solidifying or binding the material as per the instructions given by curing or binding paths which are generated earlier. Different 3D printing emerged in the last few years such as

$>$ Stereolithography (SLA)

$>$ Fused deposition modeling (FDM)

$>$ Selective laser sintering (SLS)

$>$ Selective laser melting (SLM)

$>3 \mathrm{D}$ ink jet printing (Binder Jetting)

$>$ Laminated object manufacturing (LOM)

These 3D printing techniques are capable of directly making any part of the CAD database under consideration of different process parameters like laser power, layer thickness, build orientation, Density and printing materials like poly matrix composite, thermosetting and thermoplastic polymer materials like acrylonitrile butadiene styrene (ABS), poly-lactic acid

\footnotetext{
${ }^{1}$ Department of Mechanical Engineering, University Institute of Engineering and Technology Maharshi Dayanand University Rohtak -124001 Haryana INDIA

${ }^{2}$ Department of Mechanical Engineering, University Institute of Engineering and Technology Maharshi Dayanand University Rohtak -124001 Haryana INDIA
} 
(PLA), polyamide (PA), epoxy resins. Different 3D printing materials have different applications in aerospace industries, architectural industry, food and also in medical fields for printing tissues and organs. The main drawback of 3D printed material parts by different techniques is lack of strength, durability, load bearing capacity and functionality. Now incorporation of polymer matrix composite has solved these problems up to some extent. So there is a need for further advancement in these 3D printing techniques by evaluating different factors like materials, process parameters, environmental conditions which are main obstacles.

Table 1. Various 3D printing techniques comparison

\begin{tabular}{|c|c|c|c|c|c|c|c|}
\hline $\begin{array}{l}\text { 3D } \\
\text { printing } \\
\text { technique }\end{array}$ & $\begin{array}{l}\text { Principle } \\
\text { group }\end{array}$ & Principle & Material & $\begin{array}{l}\text { Capacity } \\
\text { inches }\end{array}$ & Advantage & Disadvantage & Reference \\
\hline $\begin{array}{l}\text { Stereolithograp } \\
\text { hy (SLA) }\end{array}$ & UV hardening & $\begin{array}{l}\text { Localized co- } \\
\text { polymerizatio } \\
\mathrm{n}\end{array}$ & $\begin{array}{l}\text { Photocurable } \\
\mathrm{TiO}_{2} / \text { epoxy } \\
\text { acrylate, } \\
\text { CNT/acrylic } \\
\text { ester } \\
\text { BST/epoxy }\end{array}$ & $\begin{array}{l}7.9^{\times} 7.9 \times 9.9 " \\
10^{\prime \prime} 10^{\circ} 10^{\prime \prime} \\
20 \times 20 \times 24^{\prime \prime}\end{array}$ & $\begin{array}{l}1 \text { To print parts } \\
\text { with high } \\
\text { resolution. } \\
2 \text { No problem of } \\
\text { nozzle clogging } \\
3 \text { Most } \\
\text { commonly used } \\
\text { for dental } \\
\text { applications. } \\
\end{array}$ & $\begin{array}{l}1 \text { High cost } \\
2 \text { Concern regarding } \\
\text { cytotoxicity of } \\
\text { residual } \\
\text { photoinitiator and } \\
\text { uncured resin. }\end{array}$ & {$[1],[2],[3],[4]$} \\
\hline $\begin{array}{l}\text { Fused } \\
\text { Deposition } \\
\text { Modeling(FDM } \\
\text { ) }\end{array}$ & Extrusion & $\begin{array}{l}\text { Application of } \\
\text { liquified } \\
\text { polymers } \\
\text { using nozzles }\end{array}$ & $\begin{array}{l}\text { Thermoplastic } \\
\mathrm{s} \text { such as } \\
\text { carbon } \\
\text { nanofiber/AB } \\
\mathrm{S}, \quad \mathrm{PLA}, \mathrm{PA} \\
\text { Nylon, } \\
\text { Graphene/AB } \\
\mathrm{S} \\
\end{array}$ & $12^{\mathrm{x}} 12^{\mathrm{x}} 12^{\prime \prime}$ & $\begin{array}{l}\text { 1 Low cost } \\
\text { 2 High speed } \\
\text { 3Deposition of } \\
\text { diverse materials } \\
\text { 4 Printed parts } \\
\text { are multi } \\
\text { functional. }\end{array}$ & $\begin{array}{l}\text { 1Thermoplastic } \\
\text { polymer in only } \\
\text { usable material } \\
2 \text { Material should be } \\
\text { in filament form } \\
\text { 3Lack of } \\
\text { homogeneity in } \\
\text { disperse material. }\end{array}$ & $\begin{array}{l}{[5],[6],[2],[7],} \\
{[8]}\end{array}$ \\
\hline
\end{tabular}

\begin{tabular}{|c|c|c|c|c|c|c|c|}
\hline $\begin{array}{l}\text { 3D printing } \\
\text { technique }\end{array}$ & $\begin{array}{l}\text { Principle } \\
\text { group }\end{array}$ & Principle & Material & $\begin{array}{l}\text { Capacity } \\
\text { inches }\end{array}$ & Advantage & Disadvantage & $\begin{array}{l}\text { Referen } \\
\text { ce }\end{array}$ \\
\hline $\begin{array}{l}\text { Selective laser } \\
\text { sintering(SLS) }\end{array}$ & Sintering & $\begin{array}{l}\text { Localized } \\
\text { powder } \\
\text { melting }\end{array}$ & $\begin{array}{l}\mathrm{PCL} \text { and } \\
\text { polymide } \\
\text { powder, carbon } \\
\text { black/nylon-12, } \\
\mathrm{Al}_{2} \mathrm{O}_{3} / \text { polystyre } \\
\text { ne, silica/nylon }\end{array}$ & $\begin{array}{lr}12^{\prime \prime} & \text { in } \\
\text { diameter } & \text { and } \\
15^{\prime \prime} \text { deep } & \end{array}$ & $\begin{array}{l}1 \text { There is no } \\
\text { requirement of } \\
\text { pre-designed } \\
\text { support structure. } \\
2 \text { Good strength } \\
\text { of produced } \\
\text { parts. }\end{array}$ & $\begin{array}{l}\text { 1The parts may } \\
\text { suffer shrinkage and } \\
\text { warpage due to } \\
\text { sintering and cooling. } \\
2 \text { High cost } \\
3 \text { Parts produced with } \\
\text { powdery surface. }\end{array}$ & [3] \\
\hline $\begin{array}{l}\text { Laminated } \\
\text { manufacturing } \\
\text { technology(LOM) }\end{array}$ & Laminating & $\begin{array}{l}\text { Contouring } \\
\text { and applying } \\
\text { of sheet } \\
\text { material }\end{array}$ & $\begin{array}{lr}\text { Any } & \text { sheet } \\
\text { material } \text { foil } \\
\text { like paper, } \\
\text { metals, plastics, } \\
\text { fibers glass, } \\
\text { composite } \\
\end{array}$ & $12^{\times 2 \times 12^{\prime \prime}}$ & $\begin{array}{l}1 \text { No requirement } \\
\text { of pre-designed } \\
\text { support structure. } \\
2 \text { It is faster } \\
\text { technique. }\end{array}$ & $\begin{array}{l}\text { 1Post processing is } \\
\text { must. } \\
\text { 2Bbuilding time } \\
\text { increases as no of } \\
\text { layer increase. }\end{array}$ & [3] \\
\hline 3D inkjet printing & $\begin{array}{l}\text { Binder } \\
\text { technology }\end{array}$ & $\begin{array}{l}\text { Localized } \\
\text { application of } \\
\text { binder }\end{array}$ & $\begin{array}{l}\text { Aluminum- } \\
\text { oxide and } \\
\text { alumina-silica } \\
\text { ceramic } \\
\text { powders, PCL, } \\
\text { PLA and } \\
\text { Binder } \\
\text { materials } \\
\text { amorphous or } \\
\text { colloidal silicon } \\
\text { carbide } \\
\end{array}$ & $12^{\times} 12^{\times} 24^{\prime \prime}$ & $\begin{array}{l}1 \text { High printing } \\
\text { resolution. } \\
2 \text { Soft materials } \\
\text { with multi color } \\
\text { capability. } \\
\text { 3Llow cost in } \\
\text { comparison to } \\
\text { SLA, SLM }\end{array}$ & $\begin{array}{l}1 \text { Mechanical } \\
\text { strength of parts is } \\
\text { low. } \\
2 \text { Surface roughness } \\
\text { is high. } \\
3 \text { Presence of large } \\
\text { porosity in } \\
\text { fabricating parts. }\end{array}$ & $\begin{array}{l}{[10],[11]} \\
{[3]}\end{array}$ \\
\hline
\end{tabular}




\section{3D PRINTING TECHNIQUES}

\subsection{Stereo Lithography}

It is the first 3D printing technique which was discovered by Charle hull of 3D system inc.. The photopolymer materials like resin, acrylate which can be cured by UV laser are used during the printing process. The Basic principle is that under the initiation of photons small molecules are polymerized into large molecules and finally part is made in a vat of liquid resin. A UV laser is controlled in a desired path to discharge in the resin reservoir and then photo- curable resin will polymerize into 2D patterned layer [2]. When the first layer is cured the platform is lower down and then another layer of uncured resin is ready to be patterned [12]. Acrylic and epoxy resin polymer materials are commonly used in SLA technique. The cost of photo-curable resin materials are ranging from 80 dollars to 210 dollars per liter, which is a main barrier for implementing this technique [13]. The working principle of stereolithography (SLA) is shown in fig. 1

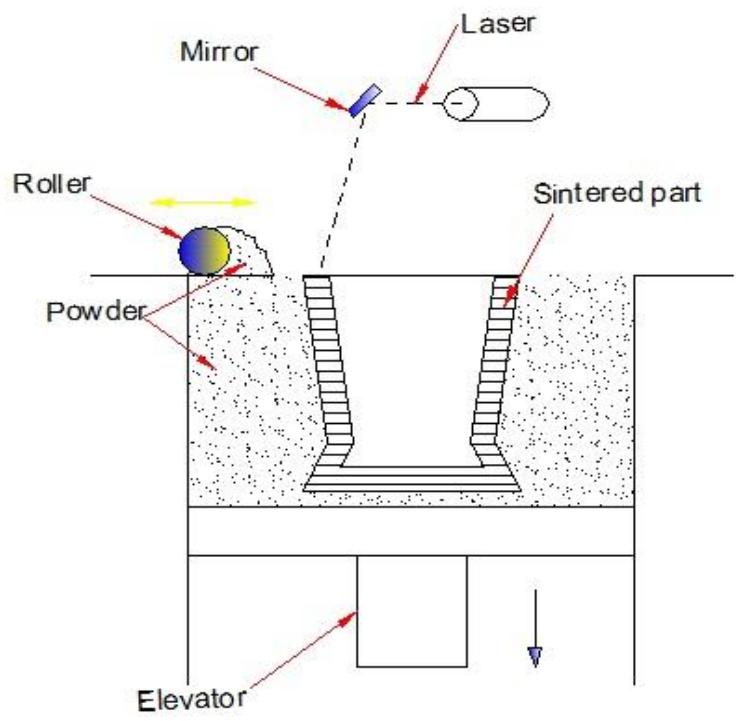

Figure 1 The Working Principle Of Stereolithography SLA

\subsection{Fused Deposition Modeling (FDM)}

It was developed by stratasys Inc. . The basic principle of this technique is extrusion process. Parts are made by deposition of extruded thermoplastic materials like polymer and synthetic stone [14]. FDM machine has three basic components, i.e. printer head, printing material and support material. Firstly printing material is fed to the printing head which will later move in $\mathrm{X}$ \& $\mathrm{Y}$ co-ordinate to print the first layer of modeled parts in CAD software by depositing the material. Now to fabricate more layers printer head base is lowered. After completion of part, supporting material is removed. Thermoplastic such as PC, ABS and PLA are commonly used due to their low melting temperature [2]. This technique can be used to improve fracture toughness with a maximum tensile strength up to $1410 \mathrm{~N}$ [5]. The strength of FDM fabricated parts is greatly affected by build orientation [6] and various types of shapes [15]. Different type shapes of pharmaceutical tablets can be printed by this technique [16] but it is significantly affected by surface area to volume ratio having the same mass but little difference in dissolution profiles. The working principle of Fused Deposition Modelling (FDM) is shown in fig. 2 


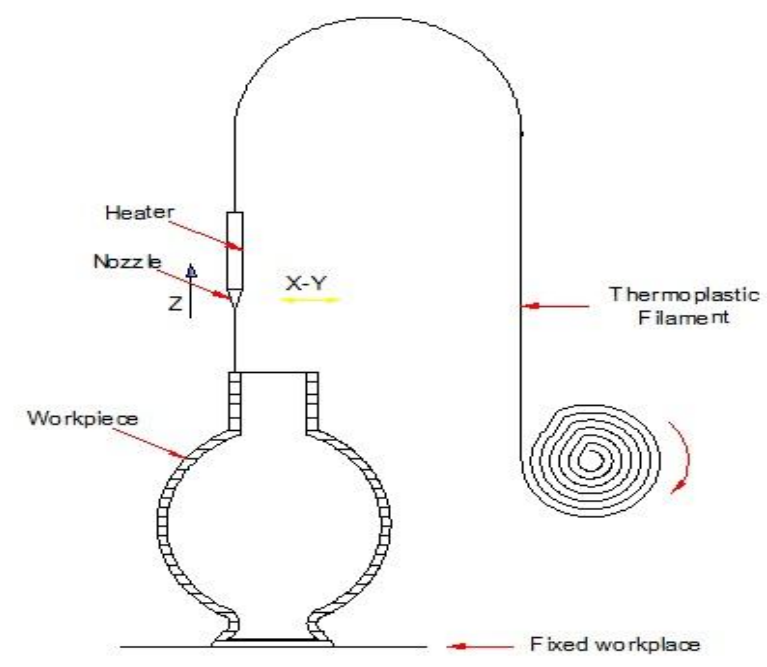

Figure 2 The Working Principle Of Fused Deposition Modelling FDM

\subsection{Selective Laser Sintering (Sls)}

It was developed by Carl Deckard \& Joseph Beaman in mechanical engineering Deptt. of university of Texas at Austin. It is an upgradation over liquid curing 3D printing technique. In SLS process a $\mathrm{CO}_{2}$ laser for sintering successive layers of powder material and a rolling mechanism is used to deposit a layer of powder on to the workplace. The powder material is preheated to a temperature slightly below its melting point. To heat up the powder to the sintering temperature laser beam is used so that the powder scanned by the laser is bonded and the un-scanned powder serve the purpose of supporting structure to the next layer to avoid any distortion. After completion of first layer roller levels another layer of powder over the sintered one for the next layer. In this technique surface quality and strength of fabricated parts are mainly affected by the laser power, temperature and part orientation [17]. The working principle of Selective Laser Sintering (SLS) is shown in fig. 3

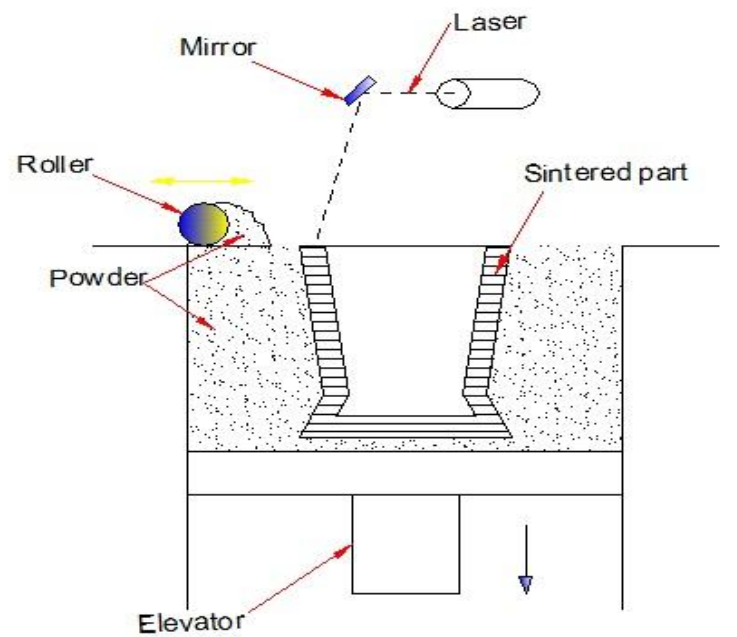

Figure 3 The Working Principle Of Selective Laser Sintering

\subsection{Selective Laser Melting (Slm)}

It is an advancement over direct selective laser sintering with the same principle of layer deposition which was developed by the Fraun Hofer ILT. The difference b/w SLS \& SLM is the material used and the melting process. When SLS is utilized to engender metal products the process is customarily referred to as SLM or Direct metal laser sintering. In SLM the material used is completely in a molten state and also already solidified material layer and actual powder layer is completely and partially melted due to solid state laser. In this way a layer by layer connection can be achieved. The working principle of Selective Laser Melting (SLM) is shown in fig. 4 


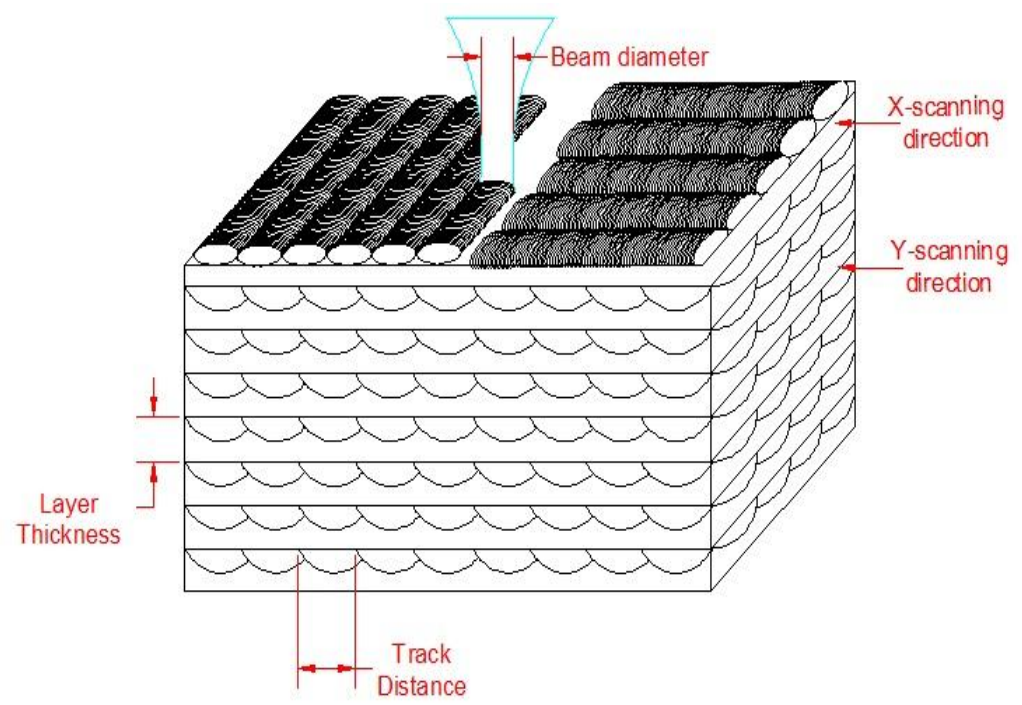

Figure 4 The Working Principle Of Selective Laser Melting SLM

\section{$2.53 d$ Inkjet Printing}

It was developed at Massachusetts Institute of Technology in which a 3D model is sliced into $2 \mathrm{~d}$ cross-section layers in a computer. A layer of powder is spread on the top of the piston, the powder bed, in a cylinder and then an ink-jet printing head projects droplet of binder material onto the powder at the place where the solidification is required according to the information from the computer model. The piston moves down a predefined distance after one layer is completed and then a new layer of powder is spread out and selectively glued. In this technique heat treatment is required to increase the bonding of the glued powder when the part is completed and then unbounded powder is removed. The double smoothing (DS) method with different layering parameters is capable of dispersing dry powder into intact ultra thin (55 micrometer) layer with removing cavity defect, layer location deviations of the printed parts [16]. This technique is extensively used in bone tissue engineering [19]. The working principle of 3D inkjet printing is shown in fig. 5

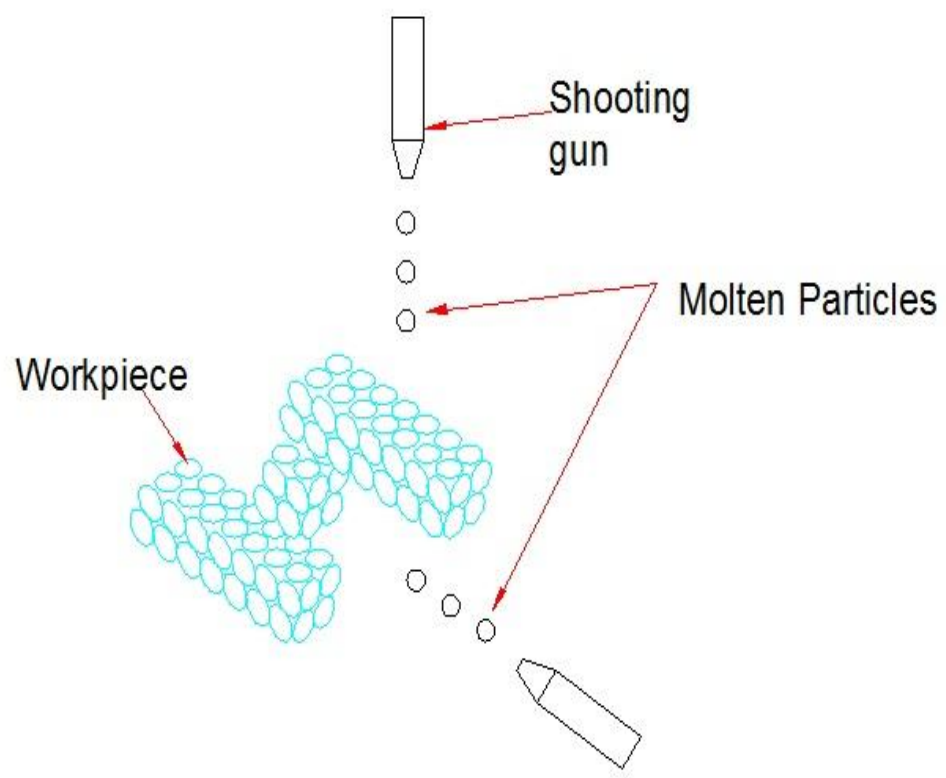

Figure 5 The Working Principle Of 3D Inkjet Printing

\subsection{Laminated Objet Manufacturing (Lom)}


As the name implies the LOM processes produce parts from thin sheets of film(paper, plastic, fibers, metal or composite). In this technique machines bond a layer of sheet material to a stack of previously formed layer and then a laser beam follows the contour of part of a cross section generated by CAD to cut it to the required shape. The layers can be welded or glued and excess material of every sheet serves as a purpose of support for the developing part. One characteristic of this technique is no requirement of pre-designed support structure because we use the solid state material in LOM process (3). LOM is faster because double or even triple layers can be cut at one time and also only profile cutting is required rather than curing a solid area. LOM parts are stronger, multilayered structures that can be used a precise pattern for secondary tooling processes such as rubber molding, sand casting and direct investment casting. The working principle of Laminated Object Manufacturing (LOM) is shown in fig. 6

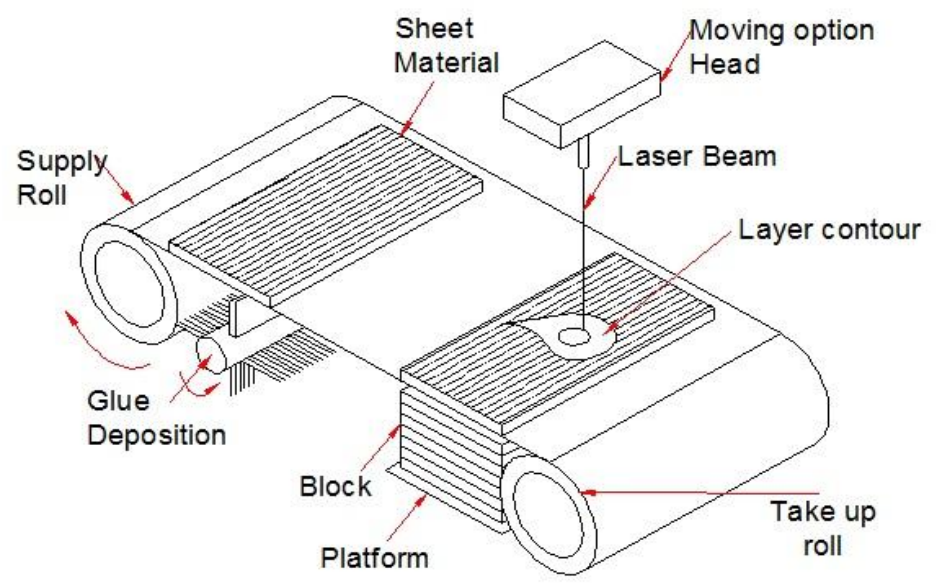

Figure 6 The Working Principle Of Laminated Object Manufacturing

\section{PROCESS PARAMETERS}

The mechanical and physical properties of the 3D printed parts are greatly affected by the various process parameters of different types of techniques such as SLA which is commonly used for dental applications find that layer thickness, depth, laser speed, builds orientation and shrinkage $b / w$ the layers are all factors that influence the mechanical and physical properties greatly [4]. The most important factors for SLA which should consider are,

$>$ Layer thickness

$>$ Build orientation

$>$ Build time

$>$ Laser speed

$>$ Scanning velocity

B.H. Lee et al. [16] used Taguchi method, an orthogonal array, main effects, the signal to noise ratio and ANOVA for optimization and investigation of FDM 3D printing process parameters i.e air gap, raster angle, raster width, and layer thickness with each having three levels of values with regard to the output performance. Finally, comparing the estimated result with experimental results found that air gap and layer thickness at $10^{\circ}$ and $20^{\circ}$ angles of displacement and raster angle at $15^{\circ}$ angle of displacement, give highest contribution to the output performance for ABS as an RP material. Joaquim de Ciurana et al. [21] Scaffold made of a biocompatible material poly-lactic acid (PLA) by the ReRap 3D printer under different process parameter like orientation, slenderness and distance $\mathrm{b} / \mathrm{w}$ filament, etc. are studied. A morphological analysis revealed that by decreasing porosity we can increase mechanical strength. Thus, some important process parameters for FDM technique are

$>$ Layer thickness

$>$ Air gap

$>$ Build orientation

$>$ Number of contours

$>$ Raster width

Pavel Hanzel et al. [9] studied the impact of selective laser melting (SLM) process parameters laser power, layer thickness, scan speed overlap rate and build direction on tensile properties and structure of steel fabricated samples. However, based on 
this study it is concluded that laser power and scanning speeds have the major effect on these properties. Nitish kumar et al. [17] used Taguchi method and an orthogonal array of experiment to optimize the effect of process parameters, i.e. laser power, cure depth, layer thickness, temp., and part orientation on powder material based SLS technique. Laser power (18.5kW) and temperature $\left(171^{\circ} \mathrm{c}\right)$ has the major effect on surface quality with max. part orientation of $90^{\circ}$. The surface characteristics and part quality in SLM and SLS are dependent on the following important process parameters.

$>$ Laser power

$>$ Layer thickness

$>$ Scan speed

$>$ Temperature

$>$ Cure depth

$>$ Hatch spacing

Hadi Miyanaji et al. [11] used binder jetting process for 3D printing of porcelain structures $\left(10^{\times 1} 10^{\times} 10^{\prime \prime}\right)$ and studied the effect of saturation level, power level, drying time and spread speed on accuracy and strength of 3D printed piece in all directions (X, $\mathrm{Y}, \mathrm{Z}$ ) and found that for optimal green part strength either of following setting could be selected (saturation level of $75 \%$, power level of $60 \%$ or $75 \%$, drying time $60 \mathrm{~s}$ or $30 \mathrm{~s}$ and spread speed of $2 \mathrm{~mm} / \mathrm{s}$ ). Thus, there are several important parameters which are greatly affecting the accuracy and strength of printed parts.

$>$ Power level

$>$ Spread speed (powder)

$>$ Drying time

$>$ Layer thickness

$>$ Powder size

$>$ Binder amount

Thus to improve the overall performance of 3D printing techniques a deep study of all these process parameters should be conducted.

\section{APPLICATIONS OF 3D PRINTING TECHNIQUES}

\subsection{Manufacturing}

The main advantages of 3D printing techniques are production of small volume batch parts with very high speed by using techniques such as SLS, SLM and FDM. However problem related to material availability and accuracy of the parts limited its use to certain parts. However 3D printing technology offer more benefits compared to traditional manufacturing techniques [22]. 3D printing techniques can also be used for photo-stress investigation of any manufactured part by depositing an optically transparent and stress sensitive material [23]. So the further development of materials used in the manufacturing industry is important for direct production of parts with 3D printing techniques. Some applications of 3D printing techniques in Manufacturing industry area:-

$>$ Fit and functional models

$>$ Pattern making for the casting process

$>$ Rapid tooling

\subsection{Design:-}

$>$ Concept modeling (product creation- visualization, design iteration)

$>$ Proof of concept (customer presentation)

$>$ Market research

\subsection{Medical application:-}

There is a lot of space for the application of 3DP technology in the medical field listed below. However, some of these applications are still in the research stage. 3DP can be used for

$>$ Surgial aids

$>$ Drug delivery systems

$>$ Bone implants

$>$ Tissue engineering

$>$ Organ printing 


\subsection{Architecture Application:-}

$>$ 3D printing and construction parts

$>3 \mathrm{D}$ printing and architectural models

$>$ Entire building project

\section{DISCUSSION}

A study of various previous research work on 3D printing techniques uncover that selection of particular techniques depends on the availability of 3D printing materials, printing machine process parameters such as speed layer thickness, laser power, build orientation, density etc., and most importantly, performance of final fabricate parts as well as its cost. SLA which is mostly used for casting geometry, functional and technical prototypes and in medical applications for fabricating surgical guides, dental cast and dental prostheses with high printing resolution. Use of liquid photo-curable materials like resins and acrylate showed the gradual improvement in accuracy and surface finish [3]. Uncured resin having high cost and cytotoxiaty has limited SLA technique applications in manufacturing industry [2]. In Manufacturing multiple drug tablets, electromechanical system and plastic toys [24,20] FDM appear as a more suitable technique with low melting temperature thermoplastics such as ABS, PC, PLA and polymer composite. Multi-material deposition capability with low cost and good strength of fabricated parts expanding their application area in other manufacturing industries of functional models and prototypes. But premature failure of fabricated parts, avoid use of this technique for manufacturing functional parts [25]. One drawback of this technique is that in the extrusion process composite material should have to be in filament form. SLS and SLM techniques which are based on the same working principle, but differ only in terms of material used are often used for the casting process. Good surface finish and size of fabricate parts are the major considerations for selecting any particular technique so SLM is a such technique which produce large size parts with high density and good surface finish in comparison to SLS where post processing is required for giving a good surface finish but distortion in parts during sintering and cooling is a major problem we often face during the SLM process [14]. Space and medical applications where we take the weight of fabricate parts into considerations, SLM is used oftenly because parts, fabricate by this process are light in weight in comparison to other techniques. In SLS and SLM, the material fusion temperature in comparison to the melting temperature of sintered powder should be low to evade oxidation and wastage of material. Previous research papers are studied for examination of material used, strength and hardness of both functional and tooling types of printed parts in 3D ink-jet technique. Ink-jet can use any material in powder form even metal for fabricating any part. For fabricating large size of functional and tooling parts over $20 \times 20^{\prime \prime}$ layers with multilayer material capability at low cost that are sufficiently thick at a speed of $.18 \mathrm{~m} / \mathrm{hrs}$ can use ink-jet printing technique [3]. The main problems in implementing this technique are the lack of availability of ink of particular material for printing the required part and blockage of the binder of a jet during the process. LOM is capable of manufacturing big models from sheet material at high speed in comparison to others 3D printing techniques. These parts can bear high pressure and less prone to fragile failure in comparison to liquid state materials fabricated parts. This technique generally finds application in manufacturing industry.

\section{FUTURE RESEARCH:-}

Although 3D printing techniques have undergone significant developments in recent years, but it is still not widely accepted by industries. The 3D printing research issue can be categorized into three groups related to:-

$>$ Material improvement

$>$ Performance improvement

$>$ Expansion of application range

The printable materials have limited the applications of 3D printing techniques because these limited materials could not meet the varied requirement of different industry applications. So availability of material must increase because now a day only thermoplastic polymer and a few photopolymers are available with low glass transition temperature and viscosity which find applications in wide area. Additional post-treatment steps involving infiltration have been used to improve the performance of printed parts, but processing time and cost has increased. The strength of parts is also low due to the presence of voids. So to eliminate the formation of void and ensure good bonding $b / w$ layers for improving performance further deep study require. Different 3D printing machines are available, but all these are time consuming and costly. So to fabricate large volume parts is impossible. Though SLA, FDM is an efficiency improvement machine, but need to develop other techniques which will be more efficient. Although these techniques have been upgraded rapidly in the current scenario, still many limitations exist now. 
Researchers are exploring many new materials, new applications of 3D printing techniques. This paper gives a platform based on which further research will progress more in terms of materials, processing control, processing stability and performance of fabricate parts.

\section{CONCLUSION}

To remain competitive in such a consumer-oriented market it is mandatory for any manufacturing industry to provide the product faster, economical, within time and also with good quality. 3D printing techniques which are generally adopted for rapid prototyping and rapid tooling can make a product faster, timely and usually at low cost than other available convention al techniques. The use of 3D printing techniques in any manufacturing industry dependent on the availability of materials, cost of printing process, process parameters of 3D printing machine and build time. So to keep in mind such factors 3D printing techniques such as SLA, FDM, SLS, SLM, 3D inkjet can be chosen. While SLA can be used to print photo-curable materials, FDM can be used to print thermoplastic materials with high speed by offering low cost and high strength, but poor surface finish in comparison to SLA and SLM. 3D ink-jet printing, which is its infancy stage still offer characteristics such as high speed, low cost of material and machine and ability to print multi-color parts simultaneously in comparison to FDM, SLS. So this technique is finding extensive use in medical and manufacturing applications with increasing its ability to produce functional graded materials (FGM).

\section{REFERENCE}

[1] R. E. Williams, S.N.Komaragiri, V. L. Melton, R. R. Bishu, Investigation of the effect of various build methods on the performance of rapid prototyping (stereolithography) Journal of Materials Processing Technology 61 (1996) 173-178.

[2] Xin Wang, Man Jiang, Zuowan Zhou, Jihua Gou, David Hui, 3D printing of polymer matrix composites: A review and prospective, Composites Part B 2016.

[3] Xue Yan and P Gu, A review of rapid prototyping technologies and systems, Computer- Aided Design. Vol. 26, No. 4, PP. 307-316. 1996.

[4] Nawal Alharbi, Reham Osman, and Daniel Wismeijer, Effects of build direction on the mechanical properties of 3D-printed complete coverage interim dental restorations. The Journal of Prosthetic Dentistry 2015.

[5] Julien Gardan, Ali Makke, Naman Recho, A metod to improve the fracture toughness using 3D printing by Extrusion method, Procedia Structure integrity 2(2016) 144-151.

[6] R.J.Zaldivar, D.B. Witkin, T.MeLouth, D.N. Patel, K. Schmitt, J.P. Nokes Influence of Processing and Orientation Print Effects on the Mechanical and Thermal Behavior of 3D-Printed ULTEM® 9085 Material S2214-8604 (16)30160-9.

[7] Omar Ahmed Mohamed, Syed Hasan Masood, Jahar Lal Bhowmik Experimental investigation of time dependent mechanical properties of PC-ABS prototypes processed by FDM additive manufacturing process S0167-577X (17)30121-0.

[8] B.M. Tymrak, M.Kreiger, J.M. Pearce Mechanical properties of components fabricated with open-source 3-D printers under realistic environmental conditions, Materials and Design 58 (2014) 242-246.

[9] Pavel Hanzl, Miroslav Zetek, Tomas Baksa, Tomas Kroupa, The Influence of Processing Parameters on the Mechanical Properties of SLM Parts, Procedia Engineering 100 (2015 ) 1405 - 1413.

[10] J.Mueller, K.Shea, C.Daraio Mechanical properties of parts fabricated by inkjet 3D printing through the efficient experimental design Material and Design 2015.

[11] Hadi Miyanaji1, Shanshan Zhang1, Austin Lassell1, Amir Ali Zandinejad2, and Li Yang, Optimal Process Parameters for 3D Printing of Porcelain Structures, Procedia Manufacturing Volume 5, 2016, Pages 870-887.

[12] P.J.Nunez, A.Rivals, E.Garcia-Plaza, E.Beamud, A. Sanz-Llobera Dimensional and surface characterization in Fused Deposition Modeling (FDM) with ABS plus 132 (2015) 856-863.

[13] H.W Kang, D.W.Cho Development of an indirect stereolithography technology for scaffold fabrication with a wide range of biomaterial selectively tissue engineering Part C methods 18 (9) (2012) 719-729.

[14] Peng Wua, Jun Wang, Xiangyu Wang A critical review of the use of 3-D printing in the construction industry 68 (2016) 21-31.

[15] Tomislav Galeta, Pero Raos, Josip Stojsic, Ivana Paksi Influence of structure on mechanical properties of 3D printed objects 149 (2016 ) 100 - 104.

[16] Alvaro Goyanes a, Pamela Robles Martinez a, Asma Buanz a, Abdul W. Basit, Simon Gaisfor Effect of geometry on drug release from 3D printed tablets, International Journal of Pharmaceutics xxx (2015) xxx-xxx.

[17] Nitish Kumara, Hemant Kumarb, Jagdeep Singh Khurmic, Experimental Investigation of process parameters for rapid prototyping technique (Selective Laser Sintering) to enhance the part quality of prototype by Taguchi method, Procedia Technology 23 (2016) 352 - 360.

[18] Shu Cao, Yang Qiu, Xing-Fang Wei, Hong-Hai Zhangl Experimental and theoretical investigation on ultra-thin powder layering in three dimensional printing (3DP) by a novel double-smoothing mechanism 220 (2015) 231-242.

[19] Mitra Asadi-Eydivanda, Mehran Solati-Hashjinb, Alireza Fathic, Mobin Padashic, Noor Azuan Abu Osman, Optimal design of a 3D-printed scaffold using intelligent evolutionary algorithms, Applied Soft Computing 39 (2016) 36-47.

[20] B.H.Lee, J.Abdullah, Z.A.Khan Optimization of rapid prototyping parameters for production of flexible ABS object Journal of Materials Processing Technology 169 (2005) 54-61.

[21] Joaquim De Ciurana, Lidia Sereno, Elia Vallesa Selecting process parameters in RepRap additive manufacturing system for PLA scaffolds manufacture Procedia CIRP 5 (2013) 152 - 157

[22] Karel Brans, 3D Printing, a Maturing Technology, 11th IFAC Workshop on Intelligent Manufacturing Systems The International Federation of Automatic Control May 22-24, 2013.

[23] Peter Ficzerea , Lajos Borbasb, New application of 3D printing method for photo-stress investigation Materials Today: Proceedings 3 (2016 ) 969 972.

[24] MitraAsadi-Eydivand, MehranSolati-Hashjin, ArghavanFarzad, NoorAzuanAbuOsman, Effect of technical parameters on porous structure and strength of 3D printed calcium sulfate prototypes, Robotics andComputer-IntegratedManufacturing37 (2016)57-67.

[25] Garrett W.Melenka, Benjamin K.O.Cheung, Jonathon S.Schofield, Michael R.Dawson, Jason P.Carey Evaluation and Prediction of the Tensile Properties of Continuous Fiber-Reinforced 3D Printed Structures Composite Structures2016. 